Nuclear Engineering and Design 37 (1976) 413-430

(c) North-Holland Publishing Company

\title{
ON FINITE ELEMENT ANALYSIS OF PIPE WHIP PROBLEMS *
}

\author{
S.M. MA \\ Bechtel Power Corporation, San Francisco, California 94119, USA
}

and

K.J. BATHE

Mechanical Engineering Department, Massachusetts Institute of Technology, Cambridge, Massachusetts 02139, USA

Received 30 April 1976

\begin{abstract}
The nonlinear dynamic finite element solution of pipe whip problems is presented. The finite element modelling used, the step-by-step incremental solution of the nonlinear equations of motion and design considerations are discussed. The influence of various physical parameters on the response of the pipe and the restraint, and the effects of using different finite element models are considered. Specific emphasis is directed to the verification of the accuracy of the solutions obtained using energy balance checks.
\end{abstract}

\section{Introduction}

The US Atomic Energy Commission, now the Nuclear Regulatory Commission (NRC), has provided specific regulations for considering the consequences of major pipe breaks that occur inside and outside the containment vessel of a nuclear power plant $[1,2]$. In the event of such an accident, the essential equipments for safe plant shutdown, namely the coolant equipment and the containment, have to be protected against damages from pipe break effects. The required protection of the equipment can be obtained by installing pipe restraints (pipe whip restraints) onto which a broken pipe would impinge. The design of the pipe whip restraints can be based on experimental data or on an analysis which, because of the complexity of the problem, is best carried out using a computer program.

Since the pipe whip analysis is relatively new and complex, a limited amount of literature is available.

\footnotetext{
* Paper Q3/5 presented at the International Seminar on Extreme Load Conditions and Limit Analysis Procedures for Structural Reactor Safeguards and Containment Structures (ELCALAP), Berlin, Germany, 8-11 September 1975.
}

Some parametric studies of pipe whip problems have been reported by Moreadith et al. [3] and Anderson and Singh [4], using special purpose computer codes, and by Palusmy et al. [5] using the ANSYS program [6]. Despite these past efforts, various problems must be investigated further. The objective in this paper is to discuss finite element modelling of the impact of the pipe on the restraint, and the selection of an efficient step-by-step solution procedure.

In the investigation the finite element analysis program ADINA [7], which is an extension of program NONSAP [8], was used to provide solutions to a series of pipe whip problems of increasing complexity. These solutions are presented in this paper and discussed. Conclusions are drawn regarding the effect of various physical parameters and the selection of appropriate numerical solution procedures. Finally, some design implications of the analytical results are pointed out.

\section{Nature of the pipe whip problem}

In the pipe whip design now widely used in practice, a gap is usually provided between the pipe section and pipe restraint to allow for thermal movement 
of pipe displacements associated with normal operations. Therefore, one distinct feature of the pipe whip problem is the analysis of impact of the broken pipe on the restraint. Since the pipe whip is a dynamic process, occurring in an extremely short time interval, the inertia forces of the pipe and its restraint system and the effect of the material strain rate are factors to be considered. Furthermore, the pipe and its restraint are expected to undergo inelastic deformations to $a b$ sorb a large portion of energy released from the broken pipe. Thus, it is important to recognize the different sources of energy absorption in the system and to find ways to account for them in the analysis.

Pipe whip analysis is usually difficult because the system is expected to experience during the history of response instances a sudden stiffening due to the pipe contacting the restraint, as well as softening due to local yielding. Both of these factors may cause difficulties when using a standard step-by-step dynamic analysis procedure, because large unbalanced residual forces can develop. Consequently, specific emphases has been given in this study to test and verify the accuracy of the numerical solution procedure used.

\section{Computer program ADINA}

ADINA is a general purpose nonlinear static and dynamic finite element analysis program [7]. The basic ADINA step-by-step incremental analysis procedure is reproduced in the Appendix. Both material and geometric nonlinearities can be considered. The user is provided with the option of specifying stiffness reformations, or equilibrium iterations, or both at selected time steps. The Wilson $\theta$-method or the Newmark method can be employed for the direct time integration. In the present investigation, the Newmark operator with $\alpha=\frac{1}{4}, \delta=\frac{1}{2}$ (average constant acceleration method) was used.

\section{Study problems}

The various objectives of this investigation stated earlier have been pursued by analyzing two different groups of problems. In the first group, Problems 1.11.5 , simple one- or two-degree-of-freedom dynamic models of a pipe and its restraint were studied. These

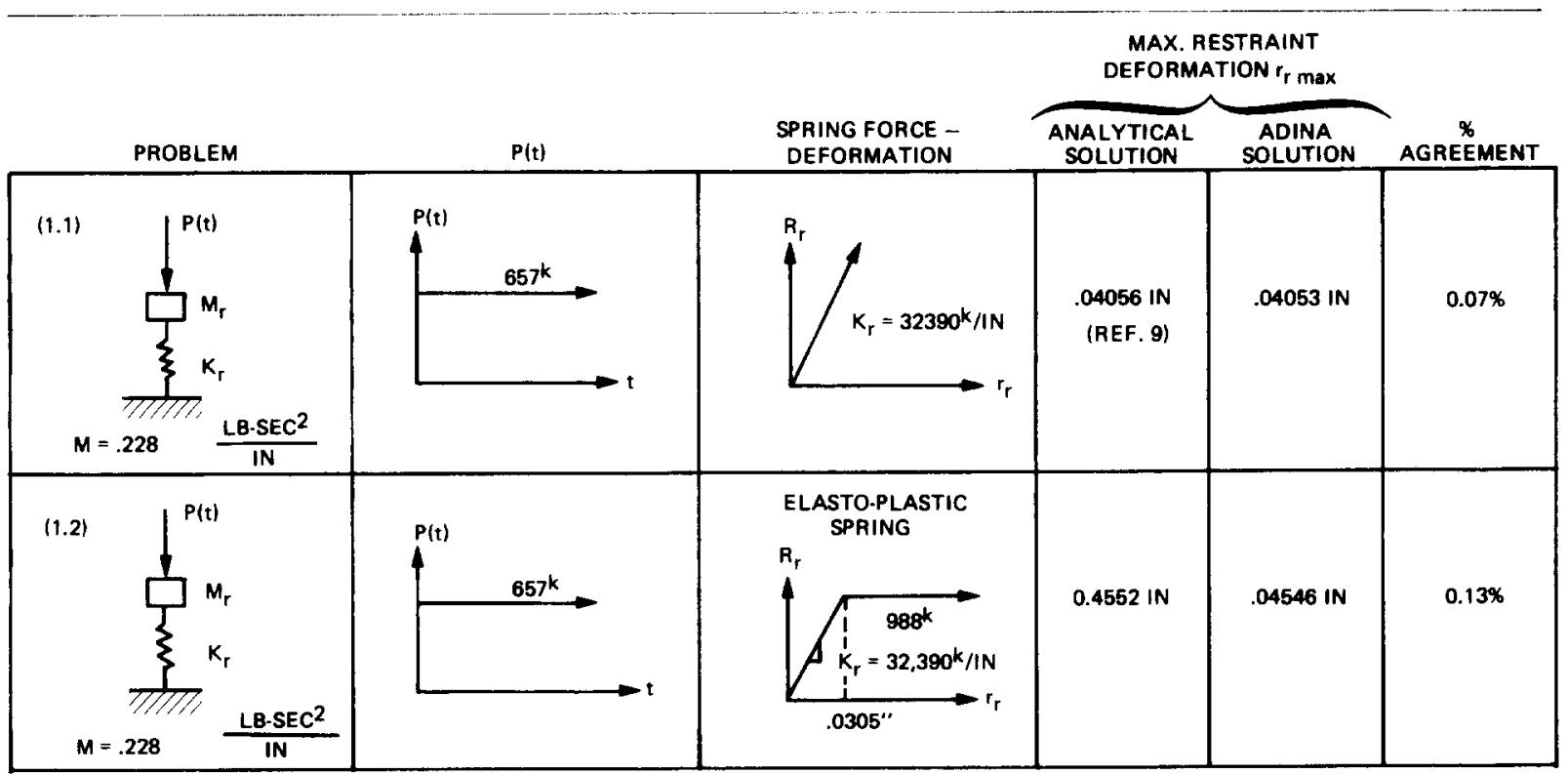


Table 2

Group 1 problems $(1.3-1.5)$.

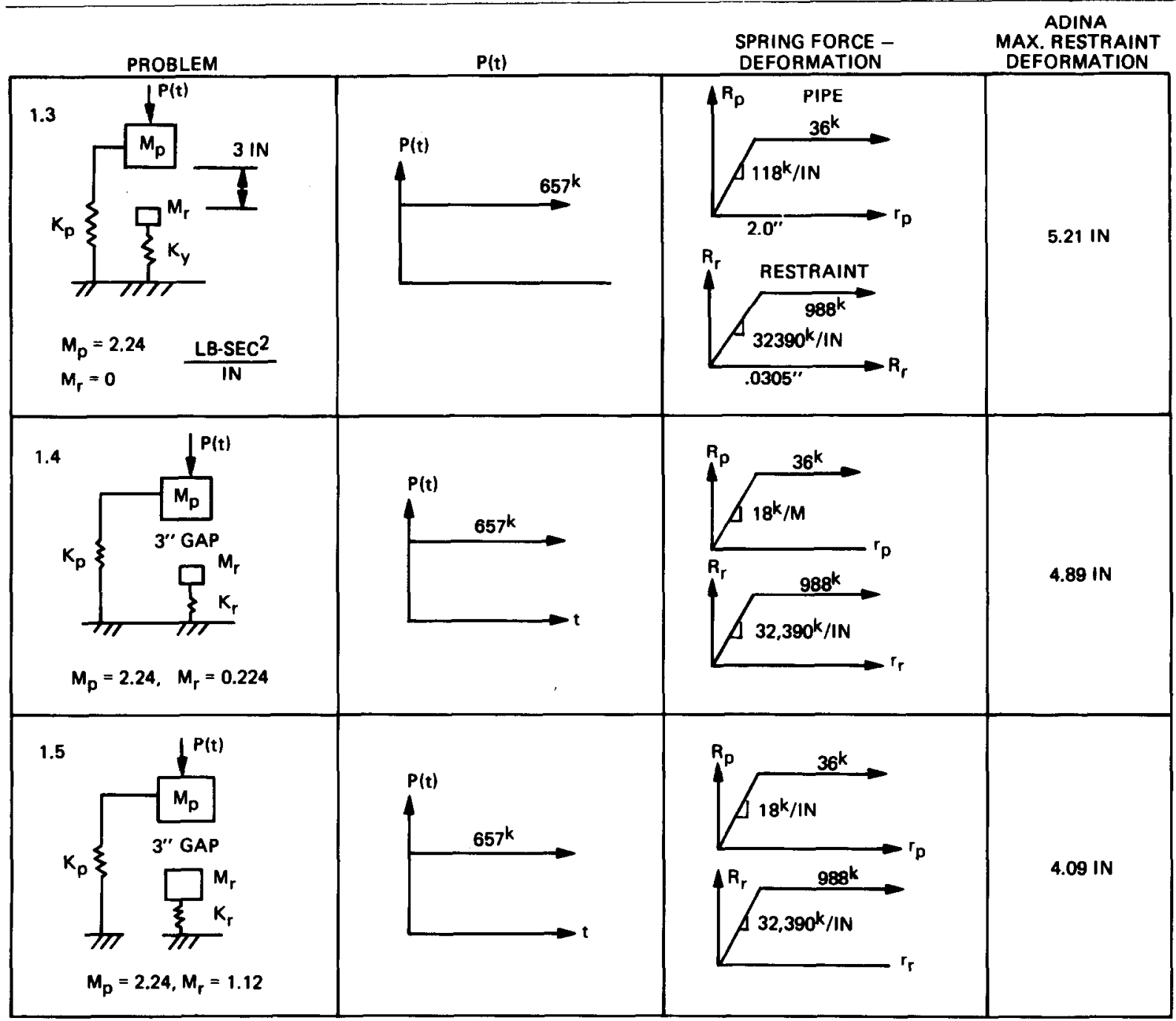

models cannot represent adequately an actual pipe whip problem, but they have been considered in order to gain confidence in the analysis procedure and to acquire a better understanding of various aspects of pipe whip analysis. Problems $1.1-1.5$ and the analytical solutions are listed in tables 1 and 2 . In the second group of problems, an actual pipe was modelled as a two-dimensional cantilever beam which is separated from the restraint by a gap, and various parametric studies were carried out using this model.

It should be noted that in all problem solutions the dynamic response was predicted from the time of load application to the time of the maximum restraint deformation. Also, the force applied on the pipe during the postulated break was characterized by a step force function.

\section{Group 1 problems}

In problems $1.1-1.5$ a few concentrated masses and springs have been used to model, in a very simplified manner, pipe whip problems. The masses and stiffnesses and the gap width used have been based on the physical 
characteristic of the pipe in fig. 7. The parameters studied include the effect of mass in the restraint, energy absorption in the pipe and restraint, and impact of the pipe on the restraint.

\subsection{Finite element models}

The finite element models used for Problems 1.1 and 1.2 and $1.3-1.5$ are shown in figs. 1 and 2 , respectively. The stiffnesses of the pipe and the restraint are modelled using truss elements. The material behavior of these elements was assumed to be linear elastic or nonlinear elastic in order to simulate elastic-perfectlyplastic behavior. This simple lumped parameter and material representation allows with relative ease insight to be gained into the stability and accuracy of the incremental step-by-step solution as discussed in section 5.2 .

The effect of the initial gap is modelled by providing an interface or gap element (truss element 2 ) with a stress-strain relationship as shown in fig. 2 . A region
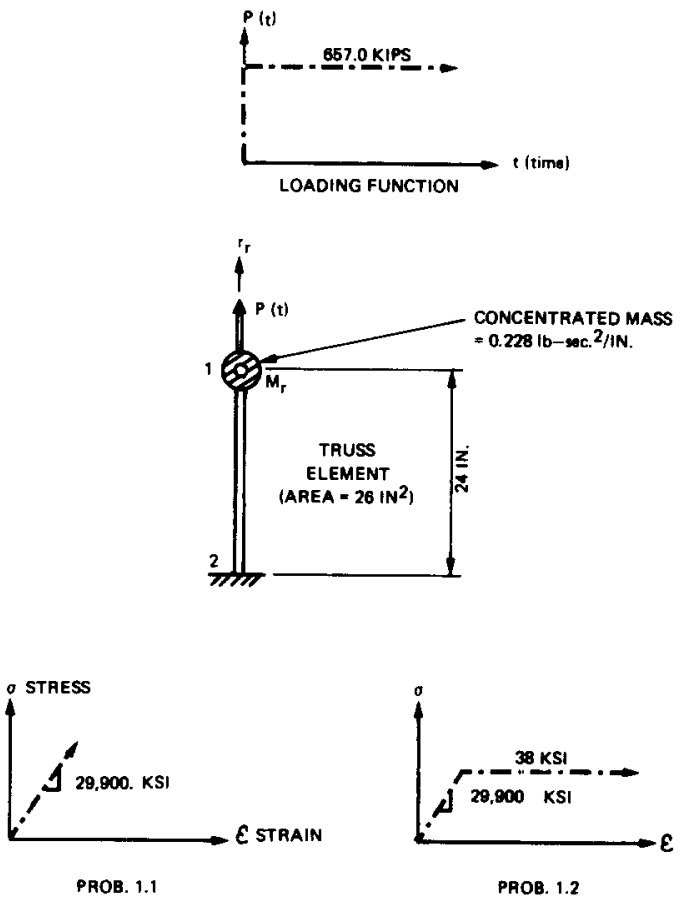

STRESS / STRAIN RELATIONSHIPS IN TENSION AND COMPRESSION

Fig. 1. Finite element models (problems 1.1 and 1.2). of zero resistance is specified to simulate the effect of the initial gap. At the point when the initial gap is closed, or when the pipe deflection reaches 3 in. (the gap width), the corresponding strain in the gap element is $-0.003 \mathrm{in}$./in. at point B. Loading beyond the gap closure point will generate resistance from truss elements 2 and 3 , which is given by $k_{\mathrm{r}}^{\prime}=k_{\mathrm{r}} /\left(1+k_{\mathrm{r}} / k_{\mathrm{g}}\right)$, where $k_{\mathrm{g}}$ is the stiffness of the gap element after gap closure, and $k_{\mathrm{I}}$ is the stiffness of the restraint element. For the large $k_{\mathrm{g}} / k_{\mathrm{r}}$ ratio used $\left(k_{\mathrm{g}} / k_{\mathrm{r}}=277\right)$, the values of $k_{\mathrm{r}}^{\prime}$ and $k_{\mathrm{r}}$ are almost identical, i.e. $k_{\mathrm{r}}^{\prime}=0.9964 k_{\mathrm{r}}$.

\subsection{Solution results}

Problems 1.1 and 1.2 require the analysis of a simple one-degree-of-freedom spring and mass system subjected to a step force function without involving impact. The exact dynamic response solutions to these problems can be found in ref. [9]. Table 1 gives the maximum restraint deformations as predicted in this study and the exact values. In the numerical solution a time step $\Delta=0.0001 \mathrm{sec}$ was used, which is onefiftieth of the fundamental period of the system. The response predictions obtained by performing stiffness reformations and stiffness reformations plus equilibrium iterations in each step were almost identical.

To solve Problems 1.3-1.5, the finite element model shown in fig. 2 was analyzed. The system parameter are given in table 2, where it should be noted that the amount of mass in the restraint was assumed as $0 \%$, $10 \%$, and $50 \%$ of that of the pipe. The step force function acting on the pipe will force the pipe to impinge on to the restraint.

For better interpretation of the numerically predicted response, some exact analytical solutions are given in fig. 3 . In the figure the time history response of the pipe when free from any restraint, and the plastic impact response are given, which have been computed as follows. Using the notation given in fig. 2, we have for $0 \leqslant t \leqslant t_{\mathrm{i}}^{-}$, where $t_{\mathrm{i}}^{-}$is the time just before impact $r_{\mathrm{p}}(0)=V_{\mathrm{p}}(0)=r_{\mathrm{I}}(0)=V_{\mathrm{I}}(0)=0.0$ and

$$
V_{\mathrm{p}}=\int_{0}^{t} a \mathrm{~d} t, \quad a=\left(P-R_{\mathrm{p}}\right) / M_{\mathrm{p}},
$$

$r_{\mathrm{p}}=\int_{0}^{t} V_{\mathrm{p}} \mathrm{d} t$ 

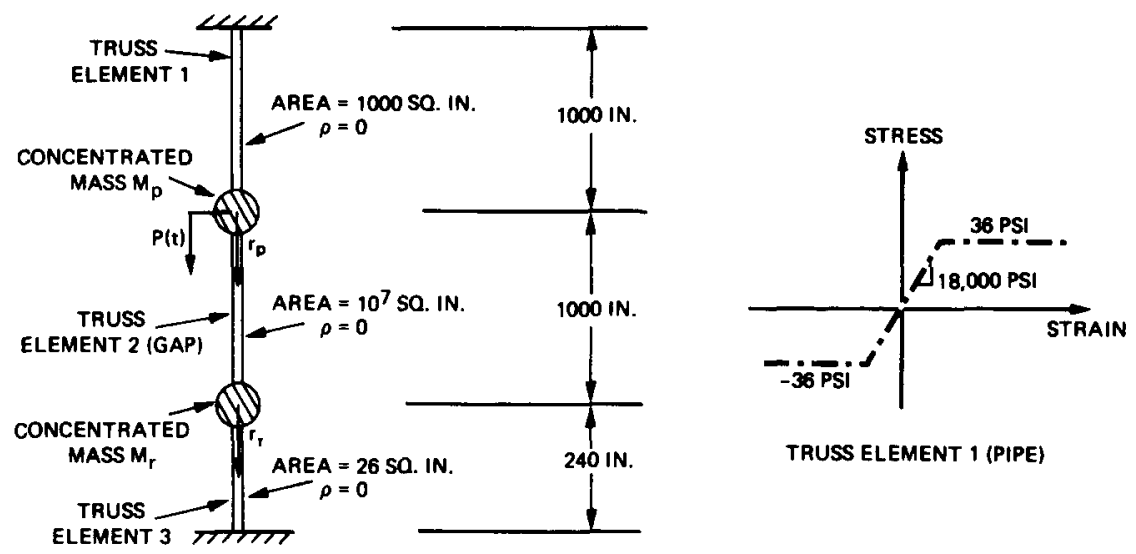

TRUSS ELEMENT 1 (PIPE)
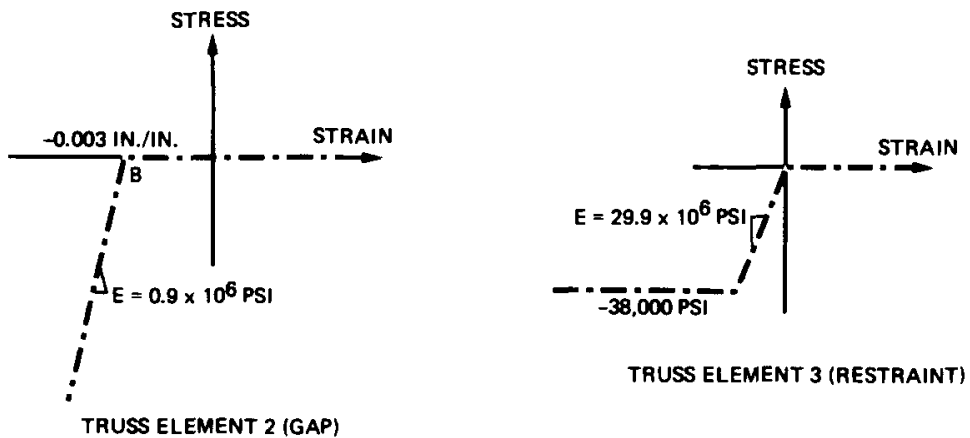

TRUSS ELEMENT 3 (RESTRAINT)

Fig. 2. Finite element models (problems 1.3-1.5).

where $R_{\mathrm{p}}$ is the internal resistnace force in the element modelling the pipe. Let $t_{\mathrm{i}}^{+}$be the time just after impact. In plastic impact the total momentum is preserved and $M_{\mathrm{p}}$ and $M_{\mathrm{r}}$ attain the same velocity $V_{\mathrm{i}}$. Thus we have

$V_{\mathrm{r}}\left(t_{\mathrm{i}}^{+}\right)=V_{\mathrm{p}}\left(t_{\mathrm{i}}^{+}\right)=V_{\mathrm{i}}=\frac{1}{1+m} V_{\mathrm{p}}\left(t_{\mathrm{i}}^{-}\right)$,

where $m=M_{\mathrm{r}} / M_{\mathrm{p}}$. The kinetic energy loss due to plastic impact is given by

$$
\begin{aligned}
\mathrm{KE}_{\text {loss }} & =\frac{1}{2} M_{\mathrm{p}} V_{\mathrm{p}}^{2}\left(t_{\mathrm{i}}^{-}\right)-\frac{1}{2}\left(M_{\mathrm{p}}+M_{\mathrm{r}}\right) V_{\mathrm{i}}^{2} \\
& =\frac{m}{1+m}\left(\frac{1}{2} M_{\mathrm{p}} V_{\mathrm{p}}^{2}\left(t_{\mathrm{i}}^{-}\right)\right),
\end{aligned}
$$

or, in words, the kinetic energy loss is equal to $m /(1+m)$ times the kinetic energy before impact. For $t \geqslant t_{\mathrm{i}}^{+}$we then have $r_{\mathrm{p}}\left(t_{\mathrm{i}}^{+}\right)=r_{\text {gap }}, V_{\mathrm{p}}\left(t_{\mathrm{i}}^{+}\right)=$

$$
V_{\mathrm{r}}\left(t_{\mathrm{i}}^{+}\right)=V_{\mathrm{i}}, r_{\mathrm{r}}=0 \text { and }
$$

$$
V_{\mathrm{r}}(t)=V_{\mathrm{p}}(t)=V_{\mathrm{i}}+\int_{t_{\mathrm{i}}}^{t} a \mathrm{~d} t ;
$$

$$
a=\frac{P-\left(R_{\mathrm{r}}+R_{\mathrm{p}}\right)}{M_{\mathrm{p}}+M_{\mathrm{r}}},
$$

and

$r_{\mathrm{r}}=\int_{t_{\mathrm{i}}}^{t} V_{\mathrm{r}} \mathrm{d} t$

The responses in fig. 3 corresponding to different mass ratios $m$ show that for a larger mass ratio the maximum energy absorbed in the restraint (or the maximum restraint deformation) $r_{\text {rmax }}$ decreases, since the amount of energy lost during the plastic impact increases as expressed in eq. (3). On the other hand, in 


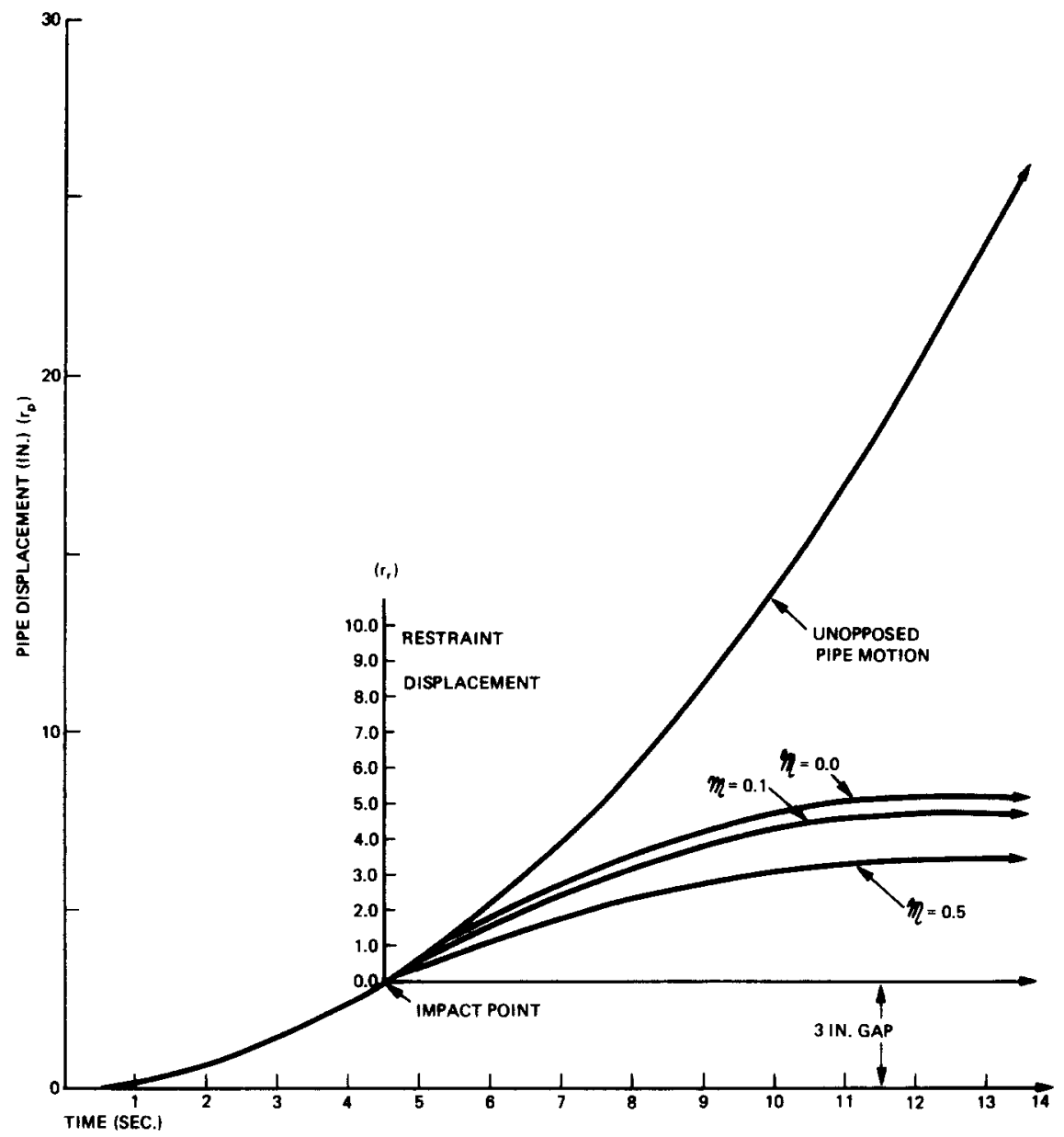

Fig. 3. Calculated plastic impact responses.

the analysis of Problems 1.1 and 1.2 the maximum restraint deformation is independent of the mass of the system; namely, we have for Problems 1.1 and 1.2, respectively;

$r_{\text {rmax }}=\left(\frac{1}{2} K_{r} r_{r \max }^{2}\right) / P$

and

$r_{\text {rmax }}=R_{\mathrm{ry}}\left(r_{\mathrm{rmax}}-\frac{1}{2} r_{\mathrm{ry}}\right) / P$,

where $r_{\text {ry }}$ and $R_{\text {ry }}$ are the displacement and internal resisting force of the restraint at yield.

Fig. 4 shows the time history solutions to problems $1.3-1.5$. These solutions have been computed using 1500 time steps and a time step $\Delta t=0.00001 \mathrm{sec}$, which is about $1 / 135$ to $1 / 165$ of the vibration of the pipe when engaged with the restraint. The response predicted using stiffness reformation at each time step and stiffness reformation plus equilibrium iterations were almost identical for the cases of small mass ratios $m=0.0$ and $m=0.10$ (Problems 1.3 and 1.4), but for a relatively large mass ratio $m=0.5$ (Problem 1.5) they are significantly different. To check the accuracy of all the solutions an energy balance relationship can be used, namely that the external work is equal to the sum of the internal energies, i.e. we have

$\operatorname{Pr}_{\mathrm{p}}=E_{\text {pipe }}+E_{\text {restraint }}+\frac{1}{2} M_{\mathrm{p}} V_{\mathrm{p}}^{2}+\frac{1}{2} M_{\mathrm{r}} V_{\mathrm{r}}^{2}$,

where $E_{\text {pipe }}$ and $E_{\text {restraint }}$ are the energies absorbed by the pipe and the restraint, respectively.

In all cases when equilibrium iteration was specified 


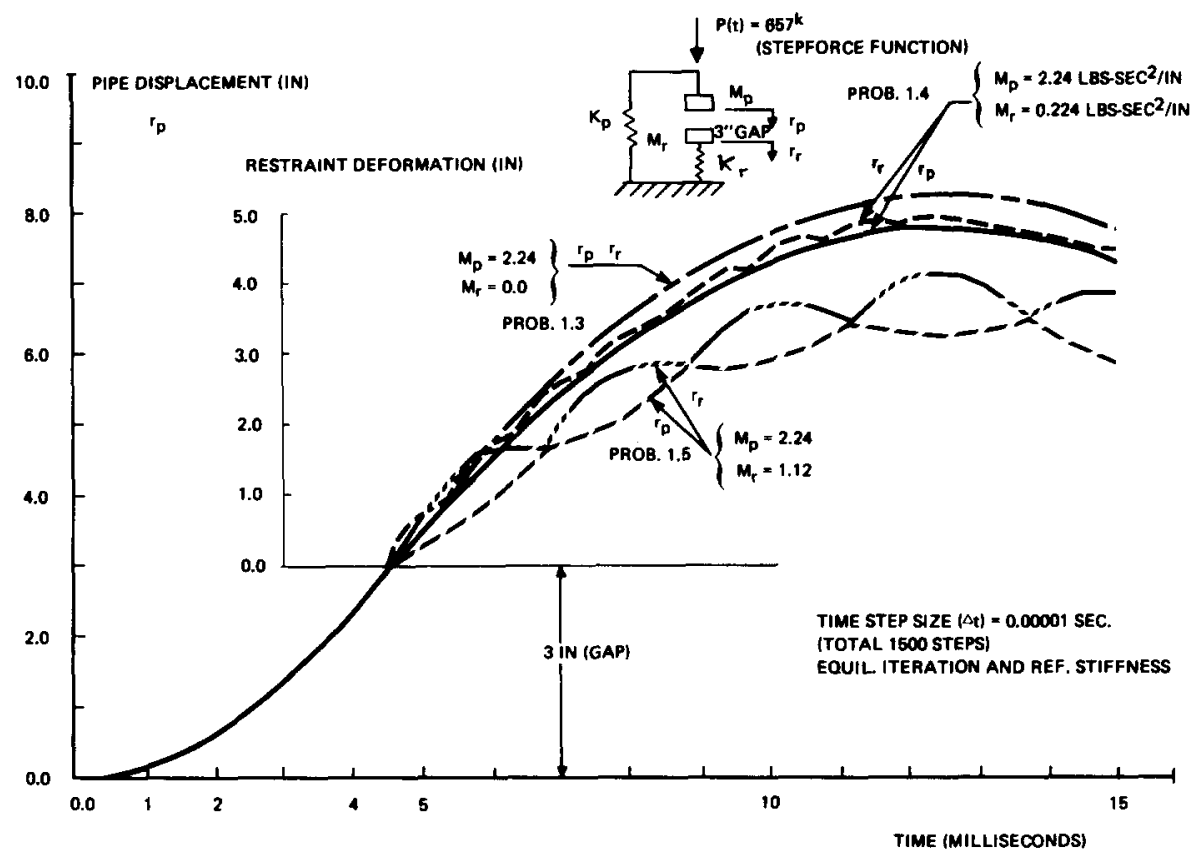

Fig. 4. Time history response of the pipe and the restraint of different pipe mass/restraint mass ratios (problems 1.3-1.5).

Table 3

Energy balance check on ADINA solutions * (problems 1.1-1.5, table 1).

\begin{tabular}{|c|c|c|c|c|c|c|}
\hline \multirow{3}{*}{ PROBLEM } & \multirow[b]{2}{*}{$\begin{array}{c}\text { EXT, WOAK } \\
\left(W_{e}\right) \\
K \text {-in }\end{array}$} & \multicolumn{4}{|c|}{ INTERNAL ENERGIES $\left(E_{i}\right)$} & \multirow{3}{*}{$\begin{array}{c}\left(W_{\mathrm{e}}-\Sigma \mathrm{E}_{\mathrm{i}}\right) / w_{\mathrm{e}} \\
\text { ENERGY } \\
\text { BALANCE } \\
\text { CHECK } \\
\text { K-in/K-in }\end{array}$} \\
\hline & & $\begin{array}{l}E_{\text {pipe }} \\
K \text {-in }\end{array}$ & $\begin{array}{c}\text { E }_{\text {restraint }} \\
K \text {-in }\end{array}$ & $\begin{array}{l}\text { K.E. (pipe) } \\
K \text {-in }\end{array}$ & $\mid \begin{array}{c}\text { K.E. (restraint) } \\
K \text {-in }\end{array}$ & \\
\hline & $\mathbf{P} r_{p}$ & $R\left(r_{p} \cdot r_{p y / 2)}\right.$ & $R\left(r_{r} \cdot r_{r y / 2)}\right.$ & $1 / 2 M_{p} v_{p}^{2}$ & $1 / 2 M_{r} V_{r}^{2}$ & \\
\hline 1.1 & 26.63 & 26.60 & - & 0 & - & $0.1 \%$ \\
\hline 1.2 & 29.87 & 29.85 & - & 0 & - & $0.1 \%$ \\
\hline 1.3 & 5078.6 & 242.3 & 4819.2 & 0.0 & 6.9 & $0.2 \%$ \\
\hline 1.4 & 4077.1 & 187.4 & 4024.9 & 0.4 & 0.15 & $3.3 \%$ \\
\hline 1.5 & 5391.3 & 258.4 & 5128.5 & 0.0 & - & $0.1 \%$ \\
\hline
\end{tabular}

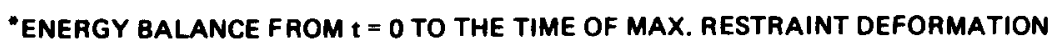


Table 4

Transfer of momentum at impact.

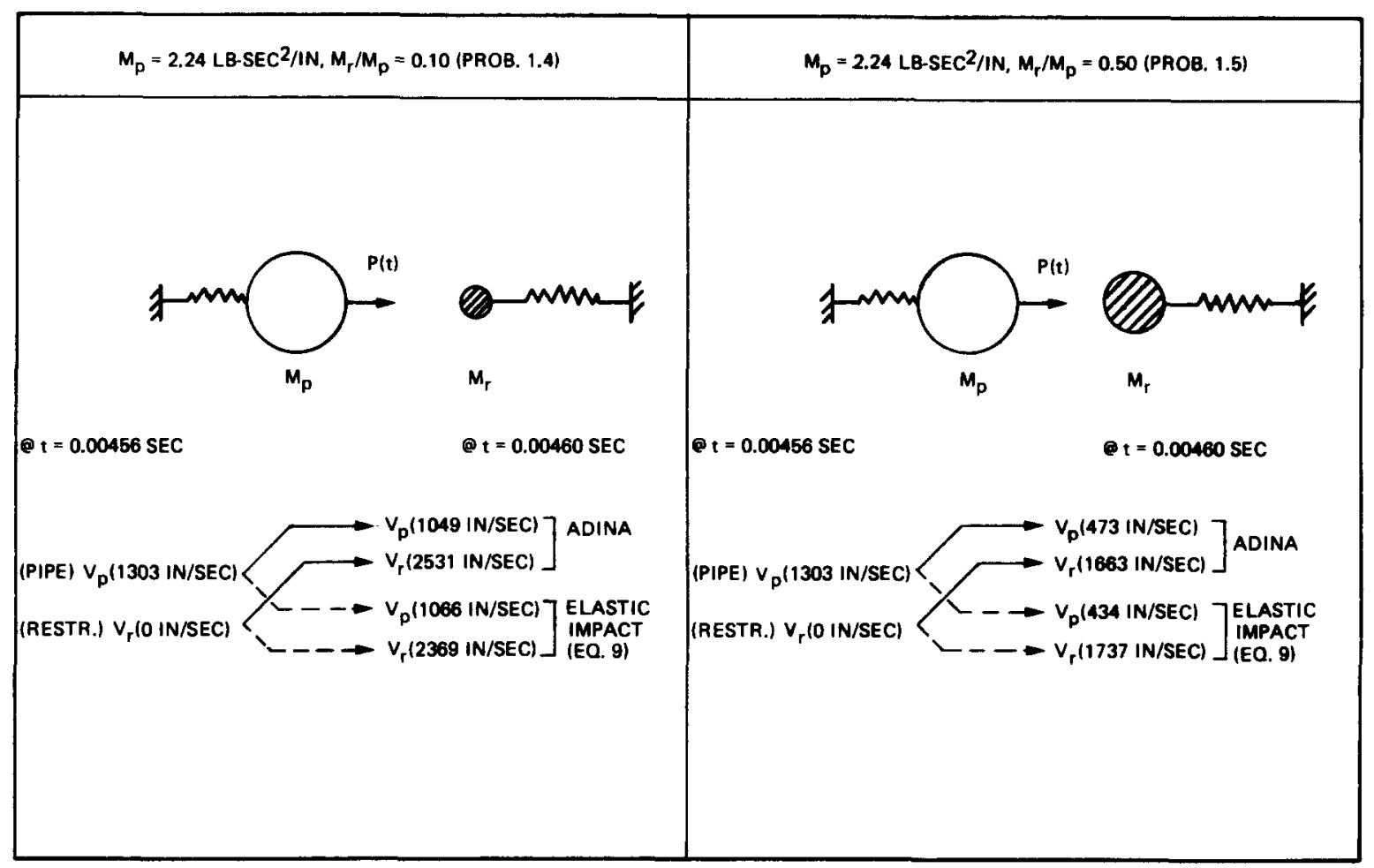

the energy balance check was excellent as shown in table 3. However, if equilibrium iterations were not specified, the energy balance check after impact could be violated by about $20 \%$ in Problem 1.5 .
The solution results in fig. 4 show that the effect of the mass in the restraint was to cause a series of separations and new collisions of the two masses after the first impact. For a larger restraint to pipe mass ra-

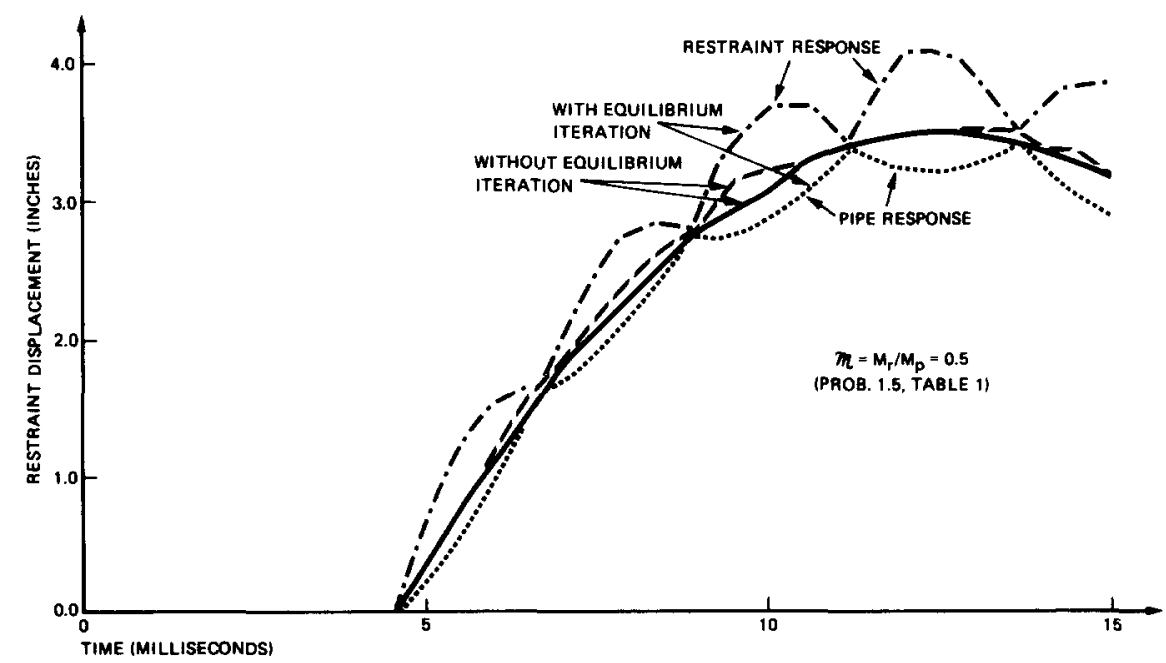

Fig. 5. Comparison between predicted restraint responses with and without equilibrium iteration. 


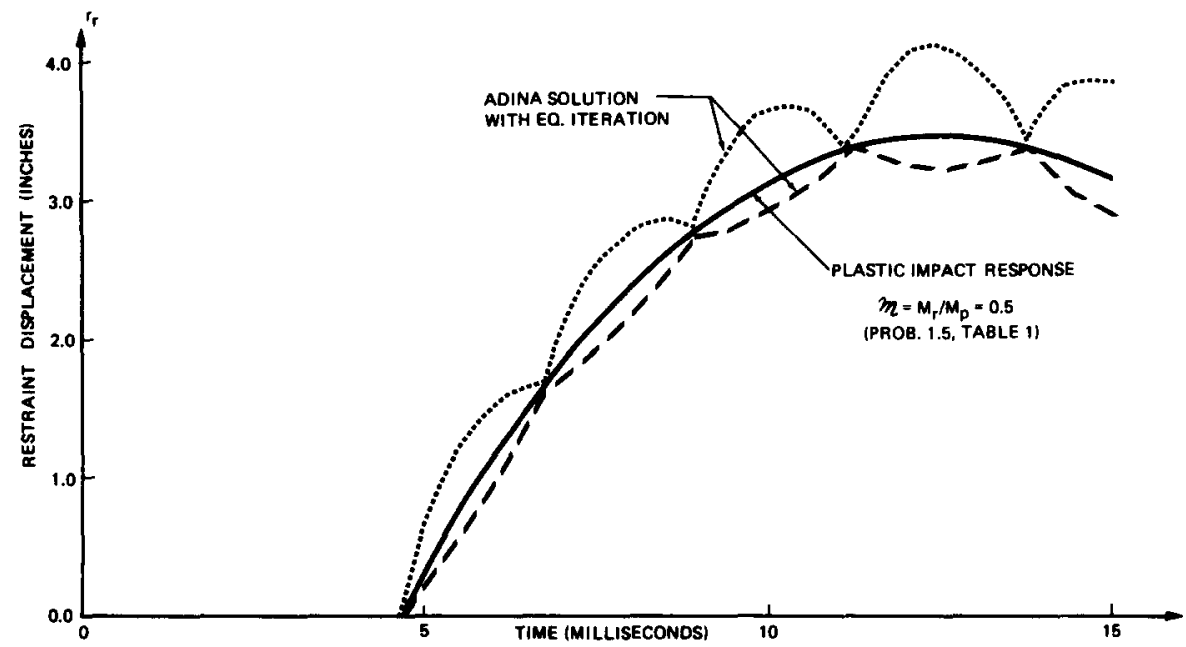

Fig. 6. Comparison between plastic impact solution and ADINA solution.

tio the maximum separation of the two masses after each collision can be significant.

The momentum transfer which took place during the impact in the numerical solutions closely match the relationships given by elastic impact theory, as shown in table 4 . The elastic impact relationships are based on the conservation of momentum and kinetic energy during impact, which yields

$V_{\mathrm{p}}\left(t_{\mathrm{i}}^{+}\right)=[(1-m) /(1+m)] V_{\mathrm{p}}\left(t_{\mathrm{i}}^{-}\right)$,

$V_{\mathrm{r}}\left(t_{\mathrm{i}}^{+}\right)=[2 /(1+m)] V_{\mathrm{p}}\left(t_{\mathrm{i}}^{-}\right)$.

The reason for the close correspondence is that impact took place in a very short time interval (in this case within the time interval of $0.00001 \mathrm{sec}$ ) and the incremental displacements that occurred during this interval were small. It follows that the changes in $E_{\text {pipe }}$ and $E_{\text {restraint }}$ in eq. (8) must be small and the kinetic energy of the system must remain almost constant during impact. Therefore, the elastic impact momentum transfer was predicted.

It should be noted that the plastic impact response solution lies between the responses predicted numerically for the pipe and the restraint. The difference between the numerical solution and the plastic impact solution is due to the fact that in elastic impact no energy is lost. Hence, the system conserves more energy in the numerical solution than is predicted assuming plastic impact.
An important point is that the numerical solution obtained in this study when equilibrium iterations were not specified was close to the plastic impact solution as shown in figs. 5 and 6 . Therefore, if unbalanced forces are not properly corrected at each time step, an artificial source of energy absorption is introduced which can lead to an over-estimation of the energy absorption capacity of the structural system.

\section{Group 2 problems}

Whereas the first group of problems was designed to study various important characteristics of pipe whip analysis and design in a very simplified manner, in the second group of problems an actual pipe and restraint shown in fig. 7 were analyzed for the loading indicated. The pipe rupture is assumed to occur at 360 in. away from the fully restrained end and directly above the pipe restraint. The pipe cross section has a 30 in. o.d. and a $1 \frac{1}{8} \mathrm{in}$. wall thickness. The restraint is a 24 in. long steel rod with a $5 \frac{3}{4}$ in. dia. The initial gap between the restraint and the pipe is $3 \mathrm{in}$. The pipe and restraint have a yield strength of $29.14 \mathrm{ksi}$ and $38 \mathrm{ksi}$, respectively. The load applied on the pipe during the pipe break is idealized as a step force loading as in Problems $1.1-1.5$. Since the pipe deflection will be relatively small, for the analysis small displacement conditions have been assumed. 

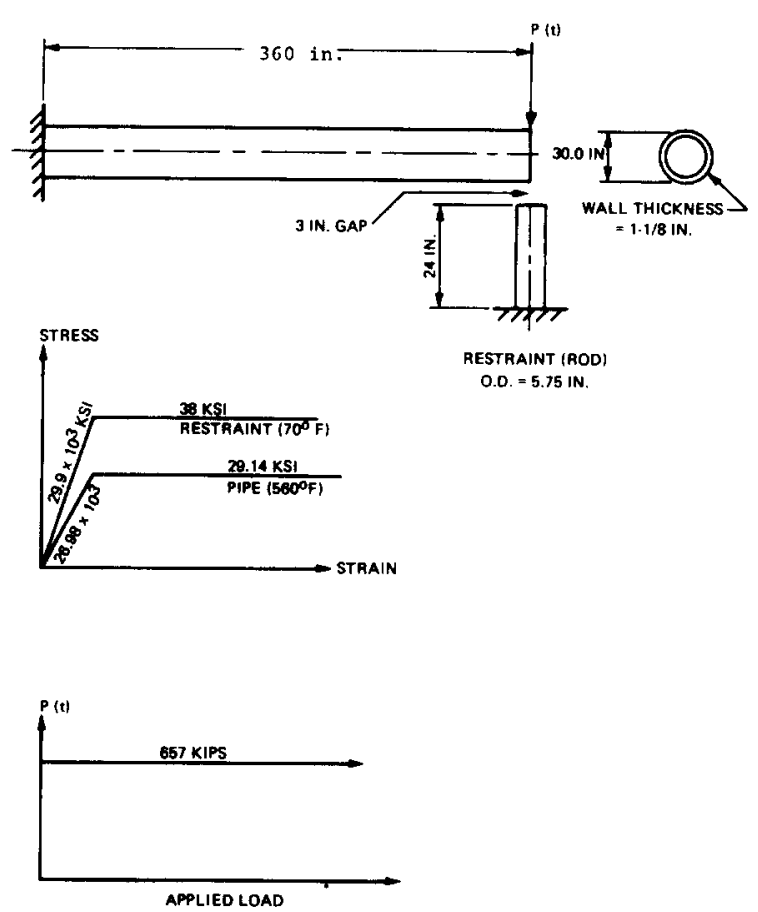

Fig. 7. Pipe whip problem.

\subsection{Finite element model}

The pipe cantilever beam was modelled as an assemblage of seven 8-node isoparametric plane stress elements as shown in fig. 8. Due to the symmetry in the stress and strain distributions above and below the pipe neutral axis, only one-half of the structure and applied load needed to be simulated. The thickness of the plane stress elements was chosen to give the same value of moment of inertia as that of the actual pipe section. In the numerical evaluation of the element stiffness matrices 3-point gauss quadrature was used, i.e. nine integration points per element have been employed, and the plastic behavior of the pipe during the dynamic response was modelled using flow theory of plasticity with von Mises yield condition. The effect of the initial gap was modelled in the same way as in the Group 1 problems, except that the effect of the gap was directly incorporated in the nonlinear stressstrain elastic-plastic relationship of the restraint (truss) element. This modelling procedure was acceptable in this particular case because the mass of the restraint was negligible and assumed to be zero.

The objective in the analysis of the finite element

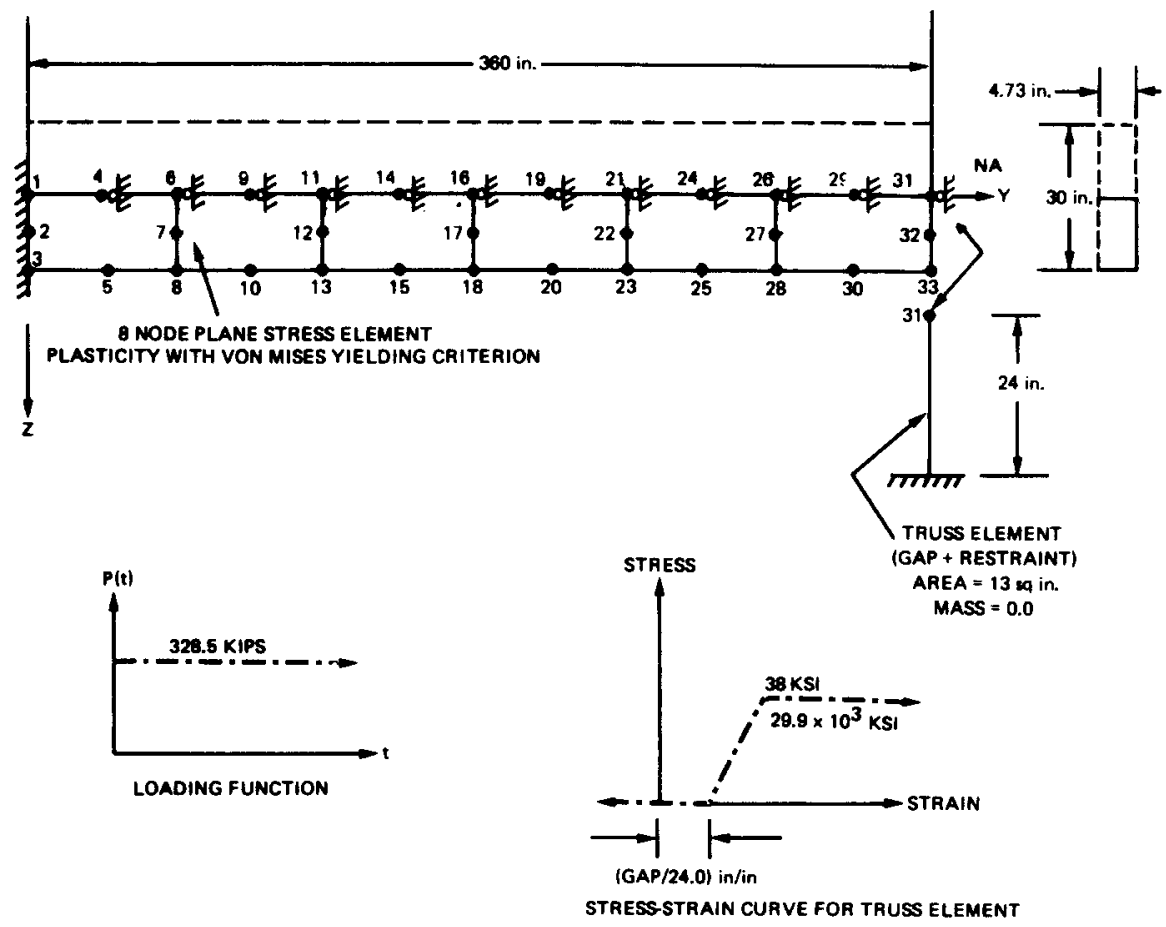

Fig. 8. Finite element model for Group 2 problems. 
model of the pipe and restraint was to evaluate

(1) the effect of using different time step sizes $\Delta t$;

(2) strategies of equilibrium iteration and reformation of stiffness matrix;

(3) the effect of using different mass models, i.e. lumped or consistent mass modelling;

(4) the effect of the gap width $r_{\text {gap }}$; and finally

(5) the effect of the yield strength of the restraint $R_{\mathrm{y}}$.

The finite element representation of the pipe described above for simulating the beam action of the pipe was thoroughly checked for elastic behavior. The analysis results assuming elastic behavior showed excellent agreement in deflections and stress with corresponding values calculated using beam theory.

\subsection{Solution results}

The effect of the time step size $\Delta t$ on the response predictions was studied by analyzing the problem given
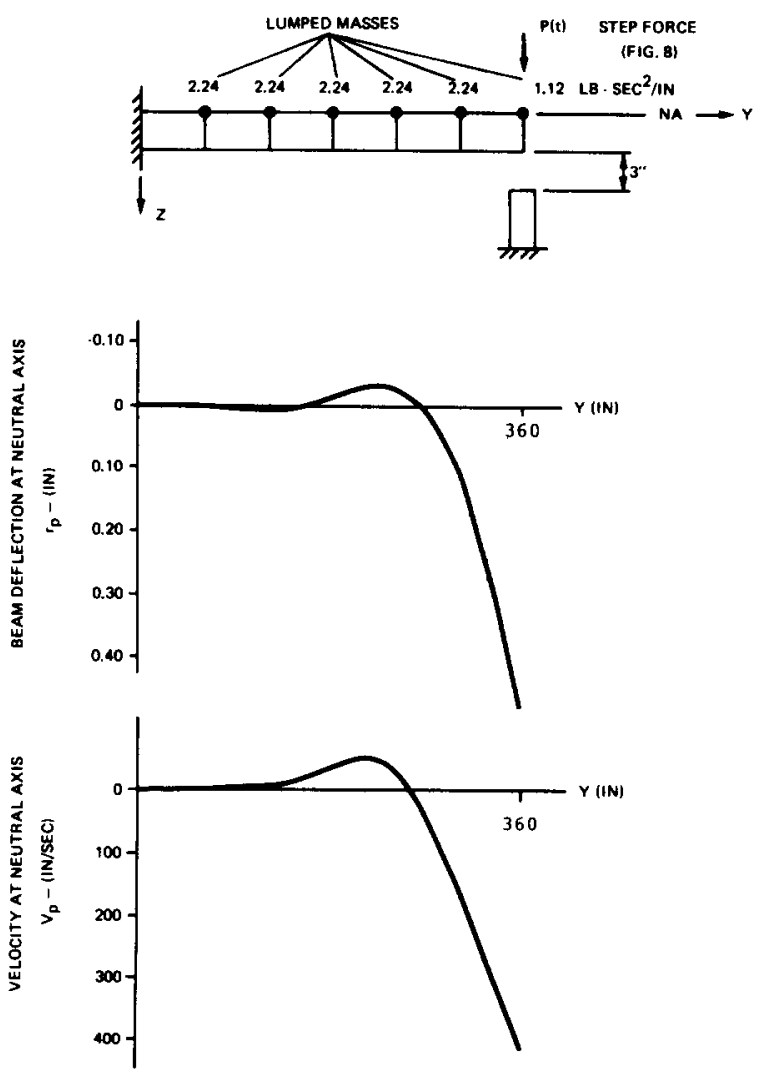

Fig. 9. Beam response at $t=0.002$ sec. in fig. 7 using $\Delta t$ values of $0.001,0.0005,0.0001$, 0.00005 , and $0.00001 \mathrm{sec}$. These time step values correspond to a $\Delta t / T_{\mathrm{f}}$ ratio of $1 / 28$ to $1 / 2800$, where $T_{\mathrm{f}}$ is the fundamental period of the structure assuming that the pipe is engaged with the restraint. The solution results using the different $\Delta t$ values did not vary significantly, and in the following only the response predicted using $\Delta t=0.00005$ is discussed.

Figs. 9-12 show the response of the pipe at various stages of loading when the mass of the beam was lumped at six nodal points along the beam. It should be noted that the first yielding did not occur at the root of the cantilever as it would be predicted in static analysis, but in a region close to the loaded end. Also, prior to the pipe engaging with the restraint, a transverse displacement wave travels along the beam from the free to the fixed end.

Considering the response of the pipe, the maximum restraint deformation occurs when the pipe tip is at
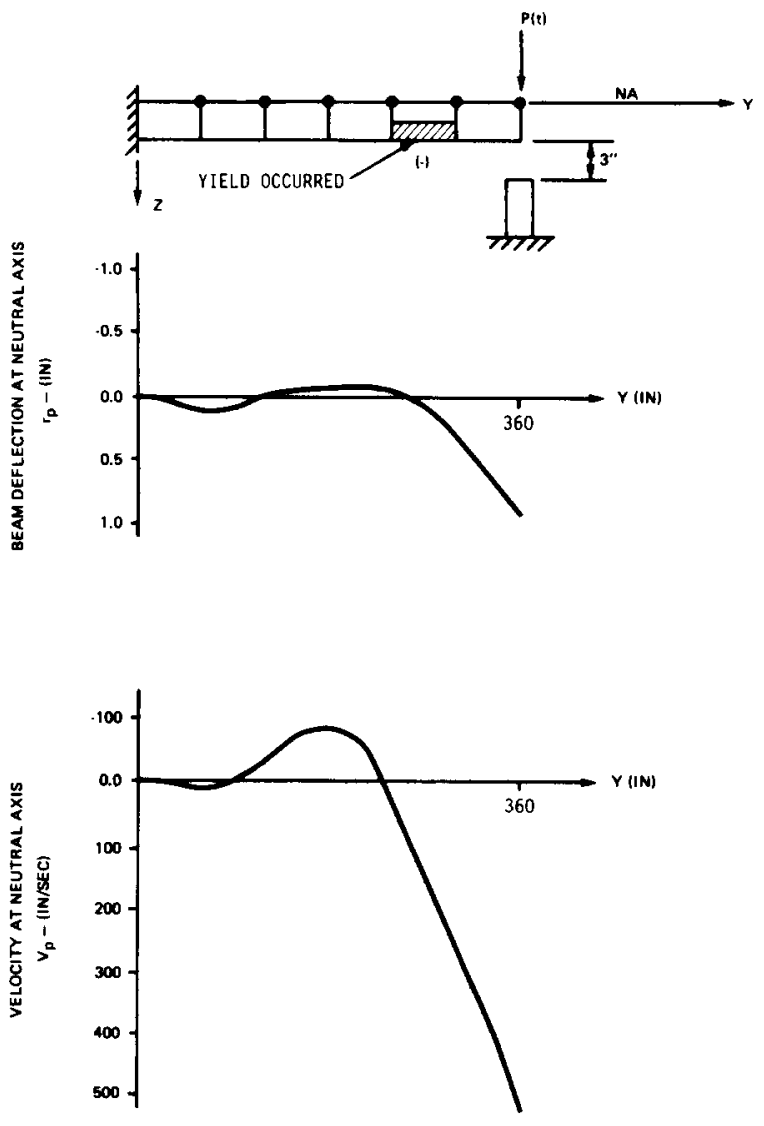

Fig. 10. Beam response at $t=0.003$ sec. 


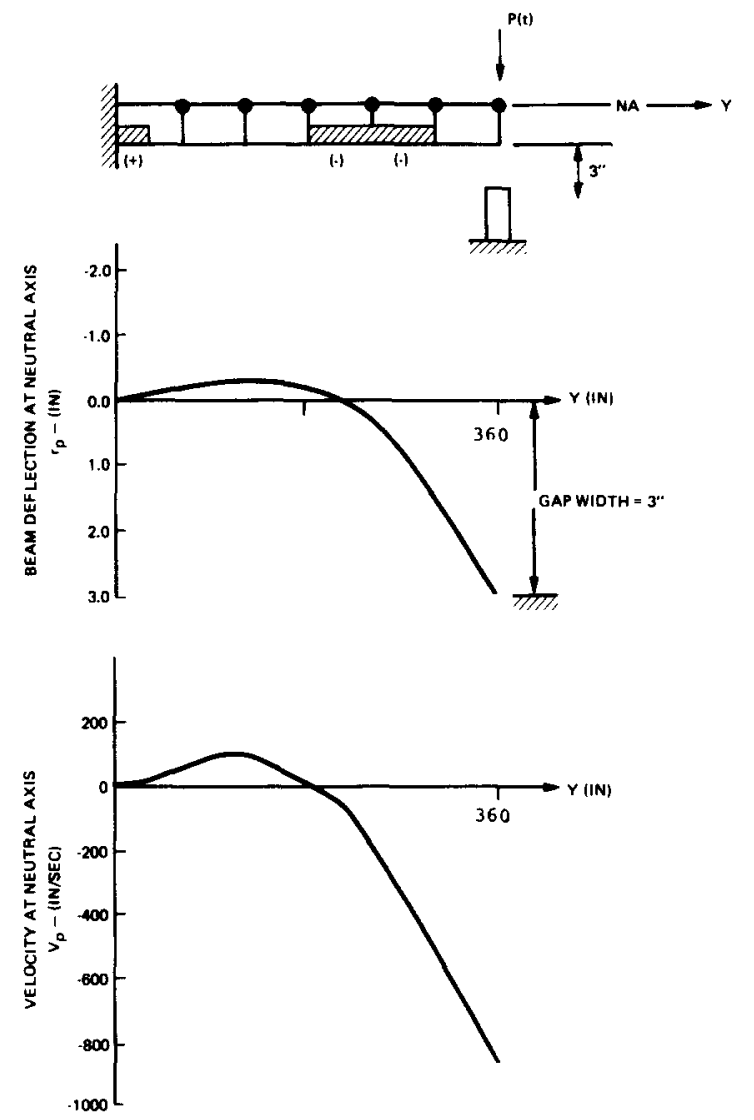

Fig. 11. Beam response at $t=0.006 \mathrm{sec}$ (just before contact).

rest. Fig. 12 shows that at that time the velocity at other points of the beam is still high indicating that only a part of the kinetic energy of the pipe has been absorbed by the inelastic deformations of the restraint.

The response of the pipe was also predicted using a consistent mass model. The solution results did not change a great deal, but the restraint deformation reached was about $10 \%$ lower.

An important consideration is the choice of an effective step-by-step procedure. For this reason, the pipe model was analyzed using the option of (1) reformation of stiffness matrix plus equilibrium iterations;

(2) using equilibrium iterations and not reforming the stiffness matrix; and

(3) reforming the stiffness matrix but not iterating for equilibrium.

The results showed no significant difference. These

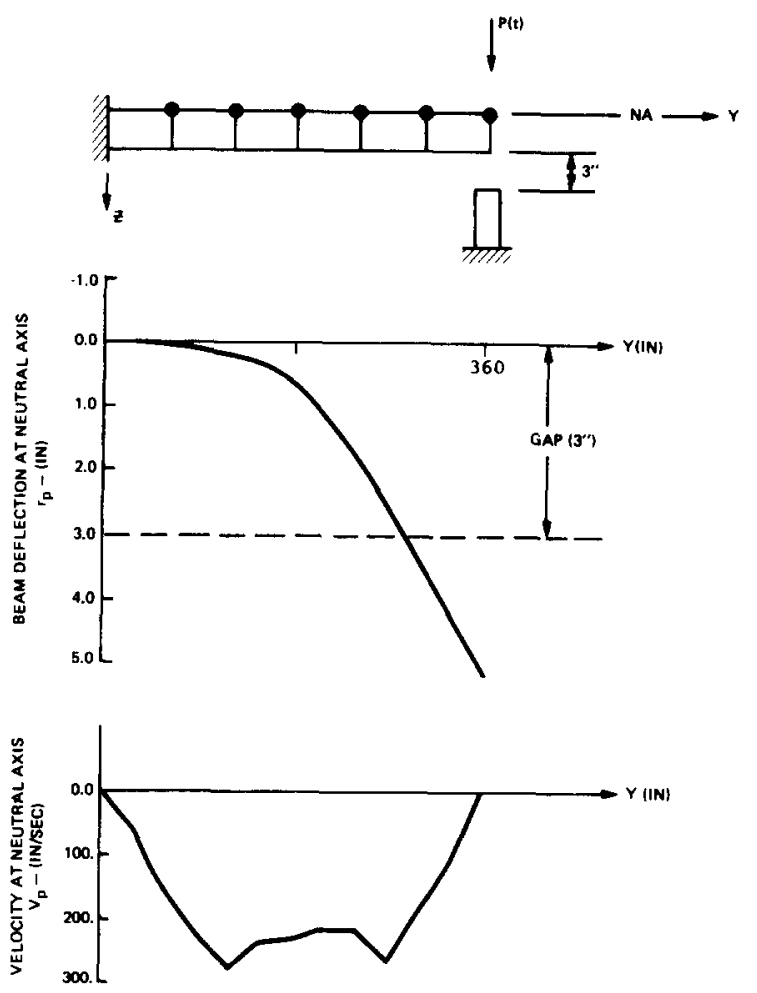

Fig. 12. Beam response at $t=0.0120 \mathrm{sec}$ (time at max. restraint deformation).

results are substantiating the observation made in the analysis of Problems 1.1-1.5, that the use of equilibrium iteration does not change the response predictions significantly provided that the mass in the restraint is negligible, which in the present case was assumed to be zero.

Fig. 13 shows the response of the pipe tip for different gap widths. It is observed that the initial gap width is a very significant parameter in determining the maximum restraint deformation, $r_{\mathrm{r} \max }$. The larger the gap the more kinetic energy is built up in the pipe which has to be absorbed later by the restraints.

The effect of using a higher yield strength for the restraint is shown in fig. 14. By increasing the yield strength of the restraint from 38 to $76 \mathrm{ksi}$, the value of $r_{\mathrm{r} \text { max }}$ is reduced from 2.2 to $0.5 \mathrm{in}$. However, the stress developed in the restraint is increased from 38 to $76 \mathrm{ksi}$, which may not be desirable because the res- 


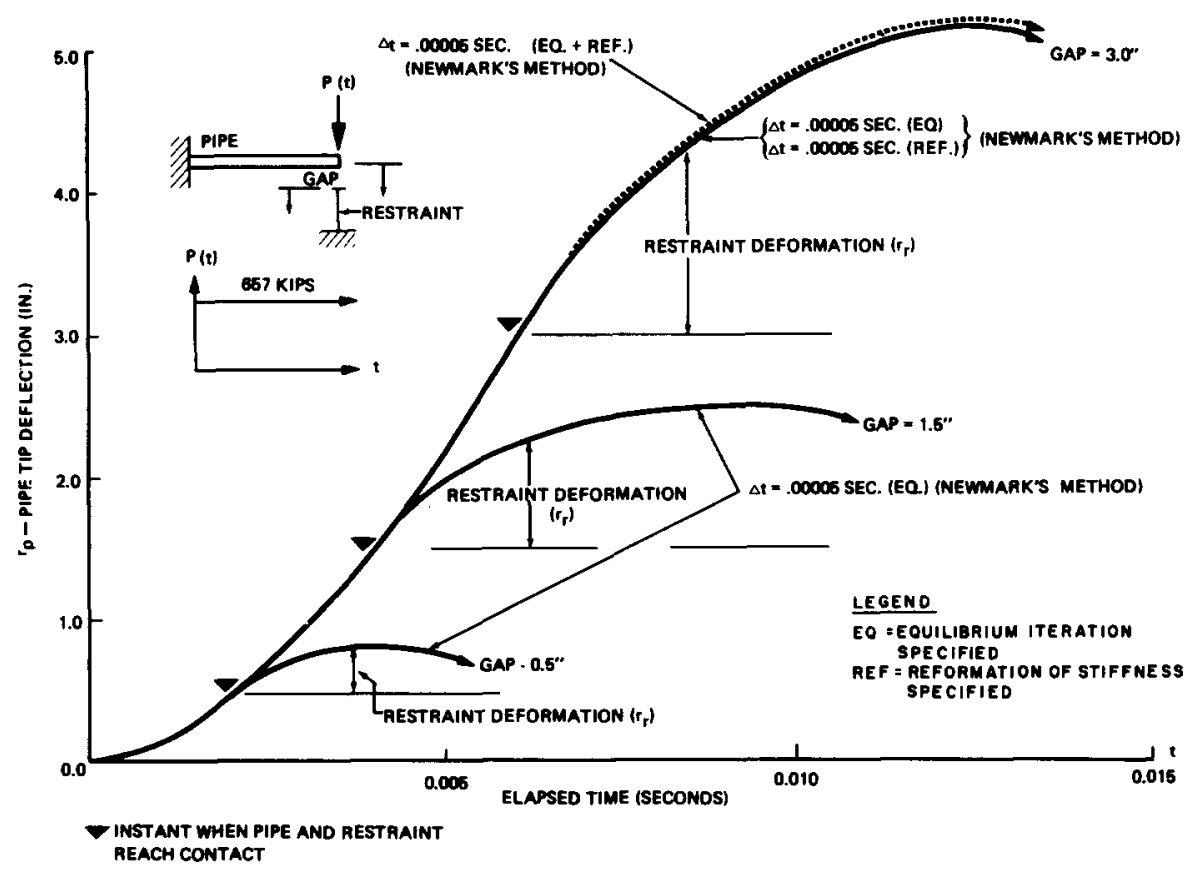

Fig. 13. Effect of initial gap.

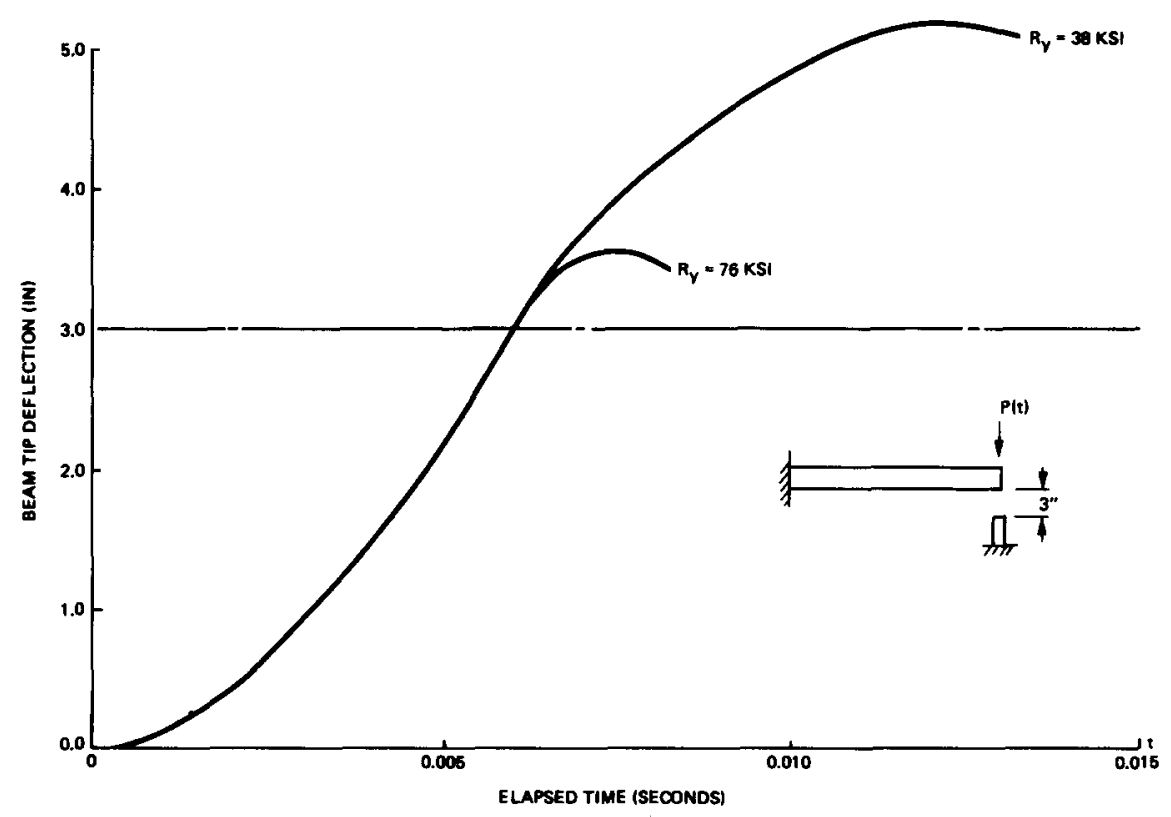

Fig. 14. Effect of the yield strength of the restraint $R_{\mathrm{y}}$. 
traint support structure has to be designed to take this increase in load.

\section{Conclusions}

Considering the numerical solution of pipe whip problems, it is important to satisfy accurately the nonlinear equations of motion throughout the response calculations. For this reason, equilibrium iteration is recommended in the step-by-step nonlinear dynamic analysis of pipe whip problems. The advantage of using equilibrium iterations is that the accuracy of the solution is ensured, thus eliminating the necessity of performing a series of runs using different time step sizes. In the pipe whip problem where the impact phenomenon is significant, the response predicted after impact without iteration can exhibit damping. Since physically a corresponding source of energy dissipation does not exist, an analysis without equilibrium iteration could lead to an unconservative prediction of the energy absorption capability of the pipe and restraint system.

The above statement is based on the assumption that convergence does occur in the iteration. If convergence difficulties are encountered, the time step size has to be decreased until the convergence criteria are satisfied [10]. For reasons of cost, it is probably most effective if the solution algorithm changes the time step size automatically to optimum values during the response calculations. Such a self-adaptive algorithm is also useful for many other types of problems [10].
In utilizing the incremental dynamic analysis procedure described in Appendix 1 the problem was able to predict closely the momentum transfer between two colliding masses (modelling the pipe and restraint) given by the elastic impact theory. This was possible by performing equilibrium iterations and without providing special constraint equations for specifying impact relationships.

Considering design aspects, it is desirable to minimize the gap between the pipe and the stop in order to keep to a minimim the kinetic energy that will be acquired by the pipe. An increase in the kinetic energy of the pipe results in a higher demand on the energy absorption characteristics of the restraint. Another means to decrease the energy absorption demand on the pipe restraint is to increase its mass, for example by attaching additional mass.

The analyses of the actual pipe whip problems reported in this paper have been carried out using standard isoparametric elements to model the pipe. Only relatively few elements were required for an adequate finite element representation. However, since the response is calculated over many time steps, the cost of solution can be significant. To reduce the analysis cost, a general three-dimensional material and geometric nonlinear special pipe element should be used for production analysis. This element must include all important nonlinear effects, and for an effective and accurate solution should be used in conjunction with a step-by-step incremental analysis procedure that is based on the above stabliity and accuracy considerations.

\section{Appendix: summary of step-by-step integration}

\section{A.1. Initial calculations}

(1) Form linear stiffness matrix $K$, mass matrix $M$ and damping matrix $C$; initialize ${ }^{0} u,{ }^{0} \dot{u},{ }^{0} \ddot{u}$.

(2) Calculate the following constants:

tol $\leqslant 0.01$; nitem $\geqslant 3$; in static analysis $\theta=1$ and go to (3).

Wilson $\theta$-method: $\theta \geqslant 1.37$, usually $\theta=1.4, \tau=\theta \Delta t$

$$
\begin{array}{llll}
a_{0}=6 / \tau^{2} & a_{1}=3 / \tau & a_{2}=2 a_{1} & a_{3}=2 \\
a_{4}=2 & a_{5}=\tau / 2 & a_{6}=a_{0} / \theta & a_{7}=-a_{2} / \theta \\
a_{8}=1-3 / \theta & a_{9}=\Delta t / 2 & a_{10}=\Delta t^{2} / 6 &
\end{array}
$$


Newmark method: $\theta=1.0, \delta \geqslant 0.50, \alpha \geqslant 0.25(0.5+\gamma)^{2}, \tau=\Delta t$

$$
\begin{array}{llll}
a_{0}=1 /\left(\alpha \Delta t^{2}\right) & a_{1}=\delta /(\alpha \Delta t) & a_{2}=1 /(\alpha \Delta t) & a_{3}=1 /(2 \alpha)-1 \\
a_{4}=\delta / \alpha-1 & a_{5}=\Delta t(\delta / \alpha-2) 2 & a_{6}=a_{0} & a_{7}=-a_{2} \\
a_{8}=-a_{3} & a_{9}=\Delta t(1-\delta) & a_{10}=\delta \Delta t &
\end{array}
$$

(3) Form effective linear stiffness matrix: $\hat{K}=K+a_{0} M+a_{1} C$.

(4) In linear analysis triangularize $\hat{K}$.

\section{A.2. For each time step}

(A) In linear analysis

(i) Form effective load vector

$$
{ }^{t+\tau} \hat{R}={ }^{t} R+\theta\left({ }^{t+\Delta t} R-{ }^{t} R\right)+M\left(a_{0}{ }^{t} u+a_{2}{ }^{t} \dot{u}+a_{3}{ }^{t} \ddot{u}\right)+C\left(a_{1}{ }^{t} u+a_{4}{ }^{t} \dot{u}+a_{5}{ }^{t} \ddot{u}\right) .
$$

(ii) Solve for displacement increments:

$$
\hat{K}^{t+\tau} u={ }^{t+\tau} \hat{R} ; \quad u={ }^{t+\tau} u-{ }^{t} u .
$$

(iii) Go to $\mathrm{C}$.

(B) In nonlinear analysis

(i) If a new stiffness matrix is to be formed, update $\hat{K}$ for nonlinear stiffness effects to obtain ${ }^{t} \hat{K}$; triangularize ${ }^{t} \hat{K}$ :

$$
{ }^{t} \hat{K}=L D L^{\mathrm{T}}
$$

(ii) Form effective load vector:

$$
{ }^{t+\tau} \hat{R}={ }^{t} R+\theta\left({ }^{t+\Delta t} R-{ }^{t} R\right)+M\left(a_{2}{ }^{t} \dot{u}+a_{3}{ }^{t} \ddot{u}\right)+C\left(a_{4}{ }^{t} \dot{u}+a_{5}{ }^{t} \ddot{u}\right)-{ }^{t} F .
$$

(iii) Solve for displacement increments using latest $D, L$ factors:

$$
L D L^{\mathrm{T}} u={ }^{t+\tau} \hat{R}
$$

(iv) If required, iterate for dynamic equilibrium; then initialize $u^{(0)}=u, i=0$.
(a) $i=i+1$.
(b) Calculate $(i-1)$ st approximation to accelerations, velocities, and displacements:

$$
\begin{aligned}
& { }^{t+\tau} \ddot{u}^{(i-1)}=a_{0} u^{(i-1)}-a_{2}{ }^{t} \dot{u}-a_{3}{ }^{t} \ddot{u} ; \quad t+\tau \\
& { }^{t+\tau} u^{(i-1)}=u^{(i-1)}+{ }^{t} u
\end{aligned}
$$

(c) Calculate $(i-1)$ st effective out-of-balance loads:

$$
{ }^{t+\tau} \hat{R}^{(i-1)}={ }^{t} R+\theta\left({ }^{t+\Delta t} R-{ }^{t} R\right)-M^{t+\tau} \ddot{u}^{(i-1)}-C^{t+\tau} \dot{u}^{(i-1)}-{ }^{t+\tau} F^{(i-1)} .
$$

(d) Solve for $i$ th correction to displacement increments:

$$
L D L^{\mathrm{T}} \Delta u^{(i)}={ }^{t+\tau} \hat{R}^{(i-1)} .
$$


(d) Calculate new displacement increments:

$$
u^{(i)}=u^{(i-1)}+\Delta u^{(i)} .
$$

(f) Iteration convergence if $\left\|\Delta u^{(i)}\right\|_{2} /\left\|u^{(i)}+t u\right\|_{2}<$ tol.

If convergence: $u=u^{(i)}$ and go to $\mathrm{C}$;

If no convergence and $i<$ nitem: go to (a); otherwise restart using new stiffness matrix and/or a smaller time step size.

(C) Calculate new accelerations, velocities, and displacements

Wilson $\theta$-method:

$$
\begin{aligned}
& t^{+\Delta t} \ddot{u}=a_{6} u+a_{7}{ }^{t} \dot{u}+a_{8}{ }^{t} \ddot{u} \\
& { }^{t+\Delta t} \dot{u}=t_{\dot{u}}+a_{9}\left({ }^{t+\Delta t} \ddot{u}+{ }^{t} \ddot{u}\right) \\
& { }^{t+\Delta t} u=t u+\Delta t^{t} \dot{u}+a_{10}\left({ }^{t+\Delta t} \ddot{u}+2 t^{t} \ddot{u}\right)
\end{aligned}
$$

Newmark method:

$$
\begin{aligned}
& t+\Delta t \ddot{u}=a_{6} u+a_{7}{ }^{t} \dot{u}+a_{8}{ }^{t} \ddot{u} \\
& t+\Delta t \dot{u}=t^{t} \dot{u}+a_{9}{ }^{t} \ddot{u}+a_{10}{ }^{t+\Delta t} \ddot{u} \\
& t+\Delta t_{u}=t_{u}+u
\end{aligned}
$$

\section{Nomenclature}

$\begin{array}{ll}a & =\text { acceleration } \\ \mathrm{KE}_{\text {loss }} & =\text { kinetic energy loss during impact } \\ E_{\text {pipe }} & =\text { energy absorbed by the pipe } \\ E_{\text {estraint }} & =\text { energy absorbed by the restraint } \\ K_{\mathrm{p}} & =\text { elastic stiffness of the pipe } \\ K_{\mathrm{r}} & =\text { elastic stiffness of the restraint } \\ M_{\mathrm{p}} & =\text { mass modelling pipe } \\ M_{\mathrm{r}} & =\text { mass modelling restraint } \\ P & =\text { applied external force } \\ r_{\mathrm{gap}} & =\text { gap width or separation between the pipe } \\ r_{\mathrm{p}} & =\text { and the restraint } \\ r_{\mathrm{py}} & =\text { pipe displacement } \\ r_{\mathrm{r}} & =\text { restraint displacement } \\ r_{\mathrm{r} \text { max }} & =\text { maximum restraint deformation } \\ r_{\mathrm{ry}} & =\text { restraint yield displacement } \\ R_{\mathrm{p}} & =\text { internal resisting force (pipe) } \\ R_{\mathrm{r}} & =\text { internal resisting force (restraint) } \\ R_{\mathrm{y}} & =\text { yield strength (restraint) } \\ t & =\text { time }\end{array}$

$$
\begin{array}{ll}
t_{\mathrm{i}} & =\text { time at impact } \\
V_{\mathrm{p}} & =\text { velocity of pipe } \\
V_{\mathrm{r}} & =\text { velocity of restraint } \\
m & =\text { mass ratio }=M_{\mathrm{r}} / M_{\mathrm{p}} .
\end{array}
$$

\section{References}

[1] Protection against pipe whip inside containment, Regulatory Guide 1.46, US A tomic Energy Commission, May (1973).

[2] Protection against postulated events and accidents outside containment, Directorate of Licensing, US Atomic Energy Commission, 12 July (1973).

[3] F. Moreadith, G. Patterson, C. Angstadt and J. Glova, Structural analysis and design of pipe whip restraints, The Specialty Conference on Structural Design of Nuclear Plant Facilities, Chicago, Illinois, 17 Dec. (1973).

[4] J.C. Anderson and A.K. Singh, Inelastic response of nuclear piping subjected to rupture forces, Piping and Pressure Vessel Conference, ASME, June, 1975, San Francisco, California, Paper 75-PVP-21.

[5] S. Palusmy, W.L. Patrick and R.L. Cloud, Dynamic analysis of nonlinear pipe whip restraints, Pressure Vessels and Piping Conference, ASME, Miami Beach, Florida, June, 1974, Conf. Paper. 
[6] ANSYS - Engineering Analysis Computer Program, Swanson Analysis Systems, Inc., Elizabeth, Penna. (1972).

[7] K.J. Bathe, ADINA - A finite element program for automatic dynamic incremental nonlinear analysis, Acoustics and Vibration Laboratory, Report 82448-1, Mechanical Engineering Department, MIT (1975).
[8] K.J. Bathe and E.L. Wilson, Nucl. Eng. Des. 29 (1974) 266-295.

[9] J. Biggs, Introduction to Structural Dynamics (McGrawHill, New York, 1964).

[10] K.J. Bathe, An assessment of current finite element analysis of nonlinear problems in solid mechanics, Proc. SYNSPADE 1975 (Academic Press, 1975). 